\title{
Swell index, oedopermeametric, filter press and rheometric tests for identifying the qualification of bentonites used in GCLs.
}

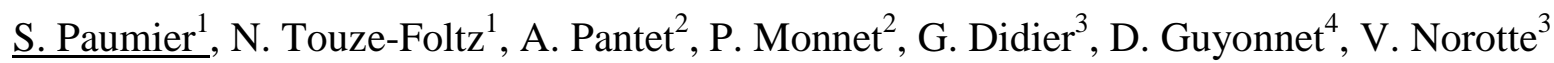

${ }^{1}$ Hydrosystems and Bioprocesses Research Unit, Cemagref, B.P. 44, 92163 Antony Cedex,

${ }^{2}$ Laboratoire d'Etudes Aérodynamiques (LEA), Université de Poitiers, ENSMA, CNRS, Téléport 2, Boulevard Marie et Pierre Curie, BP 30179, 86962 Futuroscope Chasseneuil, France.

${ }^{3}$ INSAVALOR, Géotechnique, Coulomb 3, 34 Avenue des Arts, 69621 Villeurbanne. France

${ }^{4}$ BRGM, 3 Ave. C. Guillemin, BP 36009, 45060, Orléans. France

Sandrine PAUMIER

Phone: +33140966214

Fax: +33140966270

*E-mail of the corresponding author: sandrine.paumier@cemagref.fr

\begin{abstract}
Geosynthetic clay liners (GCLs) are used in landfill liner applications and there is a need for a better control of the features of the bentonite in the GCL received on site, particularly in the European context where a wide variety of bentonites can be encountered. This paper presents the results of a project aiming at a rapid identification of the nature of the bentonite in a given GCL. The interaction between the bentonite and the fluid is increased by producing dispersions then testing its structuration in less than a few hours with filter press tests and flow curves. The results of those tests are intersected with swell index tests, electrical conductivity values and oedopermeametric tests.
\end{abstract}


Eight GCLs containing contrasted bentonite are studied. The two GCLs including natural calcium bentonite present poor swelling properties and high permittivities. The dispersions have low viscosity and their filtration under pressure leads to large amounts of filtrate. The two natural sodium bentonites and the four activated calcium bentonites have close permittivities, swell indices and filtrate masses. However, their rheological behaviours are different due to a difference in the values of electrical conductivity. Thus it seems that electrical conductivity measurements and rheological tests will provide a good and fast way of identifying the nature of the bentonite contained in GCLs.

Keywords: bentonite, cation exchange, dispersion, permittivity, viscosity, yield stress

\section{INTRODUCTION}

Geosynthetic clay liners (GCLs) typically associate a bed of granular or powdered bentonite between two layers of geotextile. For landfill bottom liner applications in France, sodium bentonite is primarily used in GCLs, meaning that it is predominantly sodium ions which constitute the exchangeable cations of the bentonite (MEEDDAT, 2008). Sodium as the exchangeable cation may be the result of natural geological processes, as for Wyoming Sodium bentonite, or else the result of an activation process whereby calcium bentonite is mixed with e.g. volcanic soda ash, to force the $\mathrm{Ca}-\mathrm{Na}$ exchange. These materials are named sodium-activated calcium bentonites. Because the term "bentonite" is an industrial and not a mineralogical term, the quality of bentonites used in GCLs for landfill applications may vary to a large extent. Bentonite is a mixture of a variety of minerals, the predominant mineral being smectite clay (Patterson and Murray 1983).

The smectite confers to the bentonite its swelling properties and its low hydraulic conductivity. Because smectite has a stronger thermodynamic affinity for divalent cations (primarily calcium and magnesium) than for sodium, the bentonite of GCLs may exchange its 
sodium for other cations if they are present in the fluids with which the GCLs come into contact (Egloffstein 2001).

Guyonnet et al. (2009) show how making the difference between a natural sodium bentonite and a sodium-activated calcium bentonite may be difficult, even for the GCL supplier. It is thus necessary to define a methodology to identify each bentonite type. The use of GCLs for landfill applications requires that these materials exhibit a low hydraulic conductivity. The oedopermeameter tests (AFNOR, 2008) allow a quantification of the hydraulic conductivity of GCLs. Such tests sometimes show large differences in hydraulic conductivity between sodium bentonites and calcium bentonites (Guyonnet et al. 2009). However these tests are very time consuming. It is thus the scope of this paper to discuss faster tests that could allow an easy distinction between the various types of bentonites.

The hydraulic conductivity of a GCL is related to the structuration capacity of the smectite. The smectite layers organise themselves in a three dimensional network that can be observed by transmission electronic microscopy (see for example Guyonnet et al. 2005). Such a structure induces specific properties that can be studied with various methods. The first of these methods is the free swell test that reflects the layers' capacity to organize themselves into a network. Many authors have tried to correlate the swell index of a bentonite with its hydraulic conductivity (Kolstad et al. 2004; Touze-Foltz et al. 2008). The results are promising and tend to show that a GCL with a highly swelling bentonite generally exhibits a low hydraulic conductivity.

To elaborate on this assumption, other tests such as rheometrical tests are sensitive enough to quantify small variations in the micro-structure (Pignon et al. 1996; Uhlherr et al. 2005; Coussot 1997). Many authors use flow tests to observe the impact of chemicals on the structuration of the bentonite dispersions (Lagaly and Ziesmer 2003; Lagaly 2006). Results reveal contrasted behaviour of bentonite dispersions according to the exchangeable complex 
of the smectite (Keren 1988; Paumier et al. 2009). According to Abend and Lagaly (2000), the electrical conductivity of the dispersion has a major impact on the rheological parameters. The electrical conductivity was also measured on bentonite dispersions to develop on this issue.

Finally, the filter press test consists in filtrating dispersions under pressure. The mass of filtrate and the physical properties of the remaining cake allow the determination of the permittivity of the dispersion in a few hours. This result is related to the swelling and the structuration of the bentonite. An attempt will be made in the following to compare results obtained in oedopermeameter and filter press tests.

In the next section, the various hydraulic and mechanical tests previously mentioned will be described. Then Section 3 will present the results obtained for 8 different bentonites, representative of materials used on the European market. Results obtained will be subsequently discussed in Section 4 of this paper.

\section{MATERIALS AND METHODS}

\subsection{The raw bentonites}

Eight GCLs were provided by three of the four main GCL suppliers operating on the European market. The products were selected such as to be representative of GCLs used in bottom liner applications, but some products were more representative of landfill cover liners (Guyonnet et al. 2009). Two GCLs contain natural calcium bentonite, two GCLs contain natural sodium bentonite and four GCLs contain sodium-activated calcium bentonite. The classical mineralogical characteristics of the bentonite inside the GCL were performed by Guyonnet et al. (2008). The clay phase proportions are in the range $68.8 \%$ to $76.8 \%$ except for LX6 (29.6\%). The CEC values are in the range $77.2 \mathrm{meq} .(100 \mathrm{~g})^{-1}$ to $88.0 \mathrm{meq} .(100 \mathrm{~g})^{-1}$ for all bentonites, except for LX6 (38.1meq. $\left.(100 \mathrm{~g})^{-1}\right)$. The amount of removable sodium differs according to the bentonite type: $66 \%$ on average for the natural sodium bentonites, $84.3 \%$ on 
average for the sodium-activated calcium bentonites and $8.9 \%$ on average for the natural calcium bentonites. The amount of removable sodium is typically overestimated in the case of sodium-activated calcium bentonites, due to artefacts related to the dissolution of $\mathrm{NaHCO}_{3}$ added during the activation process.

The hydraulic conductivities, $K_{o}$, of the raw GCLs were determined at $100 \mathrm{kPa}$ with an oedopermeameter for each GCL according to NF P 84-705 (AFNOR 2008) by Guyonnet et al. (2009). Results obtained are presented in Table 1 . The results are in the range $1.1 \times 10^{-11}$ to $3.5 \times 10^{-11} \mathrm{~m} . \mathrm{s}^{-1}$, except for the natural calcium bentonites. For these ones, the material provides a higher $K_{o}$ of $4.5 \times 10^{-9}$ for LX6 and $4.7 \times 10^{-10} \mathrm{~m} . \mathrm{s}^{-1}$ for LX8.

\subsection{Bentonite sample preparation for rheometrical and filter press tests}

The bentonites were carefully extracted from the GCLs and dispersed in $100 \mathrm{ml}$ of a $\mathrm{NaCl}$ $1 \mathrm{mM}$ solution at $10 \%$ massic concentration. The composition and ionic strength of this solution is similar to that of rainwater and was selected so as to avoid being chemically aggressive with respect to the bentonites. The dispersions are hydrated for $24 \mathrm{~h}$ including an initial mix of 3 minutes at 16,000rpm with a homogenizer (IKA Ultra-Turrax T25) then 10 mixing hours at 50rpm with a rotating shaker (Prolabo), finally $14 \mathrm{~h}$ at rest. This preparation process was defined by Paumier (2007); it allows a good homogenisation of the dispersions. The electrical conductivities of the dispersions were measured prior to performing the filter press and the rheometrical tests. For the purpose of simplicity, dispersion is defined here as a two-phase system with interactive (attractive) colloidal solid units in a low molecular liquid system as illustrated by Coussot (1997). According to Pawlick (2003) and Peysson (2004), the dispersion is stable if the mean unit size distribution is stationary in time and space over a rest period longer than the testing period. 


\subsection{Swell index tests}

Swell index tests were performed following XP P 84-703 (AFNOR, 2002) which is equivalent to ASTM D 5890 whereby two grams of dried and ground bentonite are dropped into $100 \mathrm{ml}$ of $\mathrm{NaCl} 1 \mathrm{mM}$ solution and the volume occupied by the bentonite is measured after 24 hours.

\subsection{Rheometrical tests}

The rheological measurements are performed with a Gemini HR controlled-stress rheometer (Malvern Instrument). The rheometer shears the dispersion in order to determine its mechanical properties. Experimental flow curves are obtained with $20 \mathrm{~mm}$ rough coaxial cylinders geometry. The outer cylinder, filled with dispersion, is fixed whereas the inner one is shearing the fluid (Figure 1 a). Torque applied on the inner-cylinder and its rotating speed is related to the specific rheological properties of the material. Analysis software allows a control of torque and measurement rotating speed. Shear stress, $\tau$, and shear rate, $\gamma$, are then calculated. The ratio $\tau / \dot{\gamma}$ defines the apparent viscosity $\eta$ of the dispersion.

Temperature is constantly maintained at $20^{\circ} \mathrm{C}$ to avoid effects of thermal expansion. The test parameters were defined by Paumier et al. (2008) to compare a large variety of dispersions. Before each test, a preshear at $100 \mathrm{~s}^{-1}$ was imposed for $60 \mathrm{~s}$ followed by a rest period of 180s. The controlled shear rate protocol consisted in applying successive shear rate levels from $10^{-3} \mathrm{~s}^{-1}$ to $500 \mathrm{~s}^{-1}$ by increasing then decreasing values. The shear rate steps are spread according to a logarithmic distribution. Each stress level last 20 s divided in $15 \mathrm{~s}$ of stand by the equilibration then the final point is calculated over the following $5 \mathrm{~s}$.

A short process was used for natural calcium bentonites, because their stabilities were limited. The previous test was run for 44 minutes while the short test was run for 12 minutes. The short duration avoided the risk of sedimentation of the low-concentration dispersions. 
The rest period following the preshear was reduced to $5 \mathrm{~s}$. The short protocol consisted in applying 30 successive shears rate levels from $0.1 \mathrm{~s}^{-1}$ to $500 \mathrm{~s}^{-1}$ by increasing then decreasing values. The shear rate steps are spread at regular intervals. For our dispersions, vortex due to the low viscosity appeared at shear rates higher than $250 \mathrm{~s}^{-1}$. Also, once the beginnings of the curves were represented in this article.

Three laws are used to characterize the observed behaviours: Newton's law given by Equation 1, Bingham's law given by Equation 2 and Herschel Bulkley's law given by Equation 3:

$\tau=\eta \gamma$

$\tau=\tau_{0}+\eta_{B} \gamma$

$\tau=\tau_{0}+\kappa \dot{\gamma}$

Where: $\tau$ is the shear stress; $\gamma$ is the shear rate; $\eta$ is the Newtonian viscosity; $\eta_{B}$ is the Bingham viscosity; $\tau_{o}$ is the yield stress; $\kappa$ is the consistency; and $n$ is a phenomenological coefficient.

Many complex phenomena occurred during the ascending curve, such as solid-liquid transition (Paumier et al. 2009) and the homogenisation of the dispersion inside the rheometer (Coussot 2005); therefore the model is applied only to the descending part of the curves. The yield stress is the minimum shear to apply to a dispersion to produce a flow. The physical meaning of this parameter is largely subject to discussion (Schurz 1990; Barnes 1999; Coussot 2005). To allow a comparison of the different bentonites, an approximate value was obtained from modelling the experimental curves with the model that provided the best fit (Besq et al. 2003).

\subsection{Electrical conductivity measurement}


The electrical conductivities of the dispersions were measured with a Consort $\mathrm{k} 810$ conductimeter standardized with a buffer solution at $1413 \mu \mathrm{S} . \mathrm{cm}^{-1}$. The conductimeter was equipped with a probe well suited for measuring the electrical conductivity within pastes or concentrated dispersions.

\subsection{Filter press tests}

The filter press test consists in filtrating dispersions under pressure, to acquire a filtration curve, and then determining the permeability of the residual cake. The American Petroleum Institute filtration cell is manufactured by Baroïd. It measures $90 \mathrm{~mm}$ in diameter and $90 \mathrm{~mm}$ in height. At the base of the cell, a Whatman filter paper with retention of $5-2.5 \mu \mathrm{m}$ is supported below by a wire mesh. The filtration cell containing $300 \mathrm{ml}$ of bentonite dispersion at $10 \%$ is submitted to a constant pressure of $700 \mathrm{kPa}$, by direct application of pressurised air. The pressure forces the filtrate through the filter paper, leaving a cake of clay particles that are too large to go through the filter paper (Figure $1 \mathrm{~b}$ ). The filtrate emerging from the apparatus is weighed using a balance (Sartorius $\pm 0.1 \mathrm{~g}$ ) connected to a computer, to establish the filtrate mass vs. time relationship. The filtrate mass is converted into a filtrate volume, $\omega$, assuming a liquid density, $\rho$, equal to $1000 \mathrm{~kg} \cdot \mathrm{m}^{-3}$ (Tarleton 1998). Upon filtration, the water content of the cake and the concentration of the supernatant dispersion above the cake are determined by drying the samples at $105^{\circ} \mathrm{C}$ for $24 \mathrm{~h}$.

The cake intrinsic permeability, $K$, is determined using Darcy's law. The method established by many authors assumes that the permeability and the specific volume are constant throughout the filtration (Sherwood 1997; Li et al. 1997; Pantet and Monnet 2007). Assuming that the viscosity of the filtrate was equal to the viscosity of the water, the filtrate volume vs. time square root relationship is linear as shown in Equation 4:

$$
\omega=\left[\frac{2 \Delta P A^{2} K}{\mu b}\right]^{0.5} t^{0.5}=a t^{0.5}
$$


In Equation 4, the specific volume $b$ is defined by equation 5 and the intrinsic permeability $K$ is laid to the hydraulic conductivity $k\left(\mathrm{~m} . \mathrm{s}^{-1}\right)$ according to the Equation 6 .

$$
\begin{gathered}
b=\frac{c A}{\omega_{t}} \\
K=\frac{k \mu}{\rho g}
\end{gathered}
$$

The $b$ and $K$ parameters were inserted in Equation 4, so that the expression of the permittivity $\psi_{\text {FP }}$ given by Equation 7 appeared. The permittivity was calculated thanks to Equation 8:

$\psi_{\mathrm{FP}}=\frac{k}{c}$

$$
\psi_{\mathrm{FP}}=\frac{a^{2} \rho g}{2 \Delta P A \omega_{t}}
$$

Where: $\omega_{t}$ is the total filtrate volume; $\Delta P$ is the pressure gradient; $A$ is the cross section area; $\mu$ is the filtered liquid viscosity; $t$ is time; $c$ is the thickness of the cake; and $g$ is the acceleration due to gravity.

\section{RESULTS}

\subsection{Swell index tests}

The swell index test results reveal differences between the various bentonites as shown in

Table 2. The natural calcium bentonites swell indices are lower than $10 \mathrm{~cm}^{3} \cdot(2 \mathrm{~g})^{-1}$ whereas swell indexes for the sodium-activated calcium bentonites and the natural sodium bentonites are higher than $29 \mathrm{~cm}^{3} .(2 \mathrm{~g})^{-1}$. This result is consistent with previous work on calcium and sodium bentonites (Egloffstein 2001). However, the swell index test does not allow a distinction between sodium-activated calcium bentonites and natural sodium bentonites.

\subsection{Rheometric tests results}

Rheograms obtained on natural calcium bentonite dispersions are typical of a simple viscous fluid: the viscosity is constant whatever the shear rate, as shown in Figure 2. The rheograms can be modelled using Newton's law given by Equation 1. The dispersions viscosities are 
closed to each other: they reached $4.79 \mathrm{mPa}$.s and $4.38 \mathrm{mPa}$.s for LX6 dispersion and LX8 dispersion respectively.

The mechanical behaviour of sodium-activated calcium bentonites dispersions is more complex as shown in Figure 3. At the beginning of the rheogram, the shear stresses increase over the lowest shear rate values (Paumier et al. 2009). Over this stage, the dispersion is in the solid state; it is deformed without failure or flow. The yield stress is the minimum shear stress that allows the flow; in this study it is determined by fitting the flow curve. The LX1, LX4 and LX7 rheograms are accurately modelled with Bingham's law given by Equation 2. The modelled results are presented in Figure $3(\mathrm{a}, \mathrm{d}, \mathrm{f})$. The yield stress, $\tau_{0}$ and the Bingham viscosity, $\eta_{B}$ were determined and are reported in Table 3 . The sodium-activated calcium bentonite dispersions have high yield stress and high Bingham viscosity. However LX5 has a peculiar form which probably comes from a peculiar mineralogical content or a specific activation method. LX5 rheogram was better modelled with the Herschel Bulkley's law.

The sodium-activated calcium bentonites dispersions are shear thinning; i.e. the apparent viscosity of the dispersions is a decreasing function of the shear stress. This hysteresis, which appears between the flow curves obtained with the increasing and decreasing modes, reveals the fluid's pronounced thixotropic properties (Mewis 1979; Mujumbar 2001). Thixotropic properties imply that (1) the apparent viscosity is a diminishing function of the time of flow and (2) the body recovers its initial state after a sufficient period following the end of flow.

The viscosity of the natural sodium bentonites dispersions is a diminishing function of the shear rate, the fluid is shear thinning. Therefore Bingham's law is not suitable for modelling the curves and Herschel Bulkley's law (Equation 3) is preferred (Besq et al. 2003). The yield stresses and the thixotropy are low to moderate (Table 3). The natural sodium 
bentonites dispersions are shear thinning but their apparent viscosities are lower than for the sodium-activated calcium bentonites dispersions.

These results suggest that rheological tests are able to distinguish between the various types of bentonites. The calcium bentonite dispersions are simple fluids well described by the Newton's law. The sodium-activated calcium bentonites dispersions are shear thinning, highly thixotropic and present a high yield stress. The natural sodium bentonites dispersions are shear thinning with a low to moderate thixotropy and yield stress.

\subsection{Electrical conductivity of dispersions}

A shown in Table 2, electrical conductivities measured in the dispersions, prepared for filter press tests and rheometrical tests, varied over a wide range. Furthermore, this measurement allows a differentiation between the various types of bentonite since (1) the electrical conductivities of natural calcium bentonites dispersions are lower than $0.5 \mathrm{mS}$; (2) the electrical conductivities of natural sodium bentonites dispersions are about $1.5 \mathrm{mS}$; and (3) the electrical conductivities of the sodium-activated calcium bentonites dispersions are larger than 2.3mS. The higher electrical conductivities of the sodium-activated calcium bentonites probably arise from the addition of salts to the bentonite during the activation process.

\subsection{Filter press tests results}

During the filter press test, the filtrate volume, $\omega$, is recorded over time. The filtrate curves obtained are presented in Figure 4. The natural sodium bentonites and the calcium activated bentonites curves are similar: the mass of filtrate tends toward $15 \mathrm{~g}$ of filtrate after $1 \mathrm{~h}$ of filtration. This test thus does not allow a distinction between sodium-activated calcium bentonites and natural sodium bentonites. Nevertheless a clear distinction between natural calcium bentonites and the others bentonites can be obtained. Indeed, the mass of filtrate for natural calcium bentonites is significantly larger and reaches on average $40 \mathrm{~g}$ after $1 \mathrm{~h}$ of filtration. 
The permittivities of the GCLs in the oedopermeameter $\psi_{O}$ were calculated thanks to Equation 7. The permittivities of the bentonites dispersions in the filter press are determined using the filtration curves given in Figure 4 according to Equation 8. Results are reported in Table 1. Whatever the test, the permittivities of the natural calcium bentonites are higher than the permittivities of the other materials as suggested by the filtration curves. The permittivity of the natural sodium bentonites dispersions and the sodium activated calcium bentonites are represented in Figure 5. The permittivities are in the range $1 \times 35 \times 10^{-9} \mathrm{~s}^{-1}$ to $3.61 \times 10^{-9} \mathrm{~s}^{-1}$ for the oedopermeameter test and in the range $6.44 \times 10^{-9} \mathrm{~s}^{-1}$ to $7.44 \times 10^{-9} \mathrm{~s}^{-1}$ for the filter press tests.

This comparison shows that the permittivities of the materials are close to each other wether they are determined with the oedopermeameter or the filter press. These tests do not allow differentiating the bentonite saturation. However, according to the oedopermeametric tests, GCLs LX2 and LX3 have the lowest permittivities, then LX7, LX5 and LX1 have intermediate permittivities, finally the permittivity of LX4 is slightly higher. It was interesting to observe that the same order of magnitude is observed for the filter press results. In conclusion, the filter press results are less contrasted than the oedopermeameter results. $\psi_{F P}$ are twice to five times larger than $\psi_{O}$ but the same differences between materials are observed (Table 1). This factor $\psi_{F P} / \psi_{O}$ may come from the differences between the two methods in terms of confinement and duration time.

\section{DISCUSSION}

\subsection{Distinguishing between the various bentonites}

All tests performed in this study clearly allowed distinguishing between natural calcium bentonites and sodium bentonites. The peculiarity of the natural calcium bentonites originates from the aggregation of the smectite layers in tactoids of low volume occupancy. This assumption is consistent with the rheological behaviour of a calcium-saturated smectite in dispersion at a low mass concentration, as observed by Paumier et al. (2008). This layer 
aggregation was also observed by Guyonnet et al. (2009) using transmission electron microscopy. These observations explain the low swell indices. Furthermore the particles flow easily and the viscosity of the dispersion is low. Due to their high mass, the tactoids collapse inside the dispersion which generates low dispersion stability as observed during the filter press tests. The mass of filtrate is important, which is consistent with the high hydraulic conductivity measured in oedopermeameters.

The permittivity measurement did not allow a distinction between natural sodium bentonite and sodium-activated calcium bentonite, whatever the method used. The swell indices are not able to differentiate them neither.

Regarding rheometrical tests, the sodium-activated calcium bentonites and the natural sodium bentonites in dispersions (Figure 3) deviate largely from the simple mechanical behaviour of the natural calcium bentonites dispersions (Figure 2). The dispersions are highly viscous, shear-thinning with thixotropic properties and present yield stresses of various intensities. Two rheological parameters enable to distinguish between the different bentonites: the yield stress and the apparent viscosity at a given shear rate. Sodium-activated calcium bentonites have higher yield stresses and higher viscosities than natural sodium bentonites (Figure 6). The model best suited to the observed mechanical behaviour of the sodiumactivated calcium bentonite dispersions is Bingham's law, whereas the one best suited to natural sodium bentonite dispersions is Herschel-Bulkley's law. The breakdown of the structure inside the dispersion is probably different according to the bentonite type. The links between layers may be broken abruptedly in the case of sodium-activated calcium bentonite dispersions or progressively in case of natural sodium bentonites dispersions.

\subsection{Correlation between electrical conductivity and rheological tests results.}

The electrical conductivity value and the rheometric parameters seem to be linked to each other as shown in Figure 6 where electrical conductivity is plotted as a function of two 
rheological parameters: (1) the apparent viscosity at $100 \mathrm{~s}^{-1}$; and (2) the yield stress $\tau_{o}$ used in Equations 2 and 3. There is a trend towards an increase in those parameters with an increase in the electrical conductivity. However, a larger number of points would be required in order to obtain a reliable fit.

According to Abend and Lagaly (2000), the differentiation of the form of the rheogram comes from the salt content which produce different structures. Our results confirm this hypothesis. The electrical conductivity of the dispersion comes from the natural salt content of the bentonite and possibly from the salt added to the bentonite during the activation process. As a result sodium-activated calcium bentonites have higher electrical conductivities than the natural sodium bentonites, due to salt addition and the form of the rheograms are different.

\subsection{Towards a rapid evaluation of the permittivity}

In this study two permittivities values were reported for each material: the first one determined during oedopermeameter tests performed on the GCLs, the second one determined by filtration, under pressure, of the bentonite extracted from the GCLs and dispersed. When $\mathrm{NaCl} 1 \mathrm{mM}$ is the contacting fluid, the results are close as shown in Table 1. It is suggested here that the filter press test may provide an indication of oedopermeameter test results. The significant advantages of the filter press tests are low equipment costs and the testing speed (approximately an hour). However, the filter press tests are performed on bentonite dispersions and therefore do not take into account the mass per unit area of the GCL nor the bounding process of the GCL (woven or needle punched) that may have an impact on the performance of the GCL on site. Moreover the oedopermeameter test allows reproducing the confinement characteristics of the GCLs in use which is not possible with the filter press tests. The oedopermeameter test (AFNOR, 2008) and ASTM D 5887 thus remains the only laboratory test for investigating the influence of these parameters. 


\section{CONCLUSION}

The aim of this paper was to evaluate the ability of various tests to identify the nature of the bentonite contained in GCLs. Results obtained show that a distinction between natural calcium bentonites and sodium bentonites can be obtained using swell index tests or permeability tests that can be either the long-duration oedopermeameter tests or else filter press tests. However, those tests do not allow a distinction between natural sodium bentonites and sodium-activated calcium bentonites. Rheometrical tests and electrical conductivity measurements were found to be the best methods for distinguishing between these two types of sodium bentonites.

There appears to be a relationship between mechanical parameters and the electrical conductivity. However a large number of experimental points would be necessary in order to establish a clear correlation.

This study also allowed a comparison between the permittivities obtained from filter press tests and oedopermeametric tests. According to these preliminary results, the filter press tests may provide in a few hours an indication on the long-term results of the oedopermeameter tests.

\section{ACKNOWLEDGEMENTS}

The LIXAR2 project was supported by the French Environment Agency (ADEME), waste operators SITA and Véolia-Propreté and GCL suppliers CETCO, HUESKER and NAUE.

\section{NOTATION}

Basic SI units are given in parentheses.

$A \quad$ area section of the filter press $\left(\mathrm{m}^{2}\right)$

$a \quad$ slope of the filtrate volume vs. time square root relationship $\left(\mathrm{m}^{3} \cdot \mathrm{s}^{-0.5}\right)$

$b \quad$ specific volume (dimensionless)

CEC cation exchange capacity (meq. $(100 \mathrm{~g})^{-1}$ )

c thickness of the cake (m) 
$\Delta P \quad$ pressure gradient applied to the filter press $(\mathrm{Pa})$

$g \quad$ acceleration due to gravity $\left(\mathrm{m} . \mathrm{s}^{-2}\right)$

$\omega \quad$ filtrate volume $\left(\mathrm{m}^{3}\right)$

j shear rate $\left(\mathrm{s}^{-1}\right)$

$\eta \quad$ newtonian viscosity (Pa.s)

$\eta_{B} \quad$ Bingham viscosity (Pa.s)

$K \quad$ cake intrinsic permeability $\left(\mathrm{m}^{2}\right)$

$k \quad$ hydraulic conductivity of the cake in the filter press $\left(\mathrm{m} \cdot \mathrm{s}^{-1}\right)$

$k_{O} \quad$ hydraulic conductivity of the GCL in the oedopermeameter $\left(\mathrm{m} . \mathrm{s}^{-1}\right)$

$\kappa \quad$ consistency $\left(\mathrm{Pa} . \mathrm{s}^{\mathrm{n}}\right)$

$\mu \quad$ filtered liquid viscosity $\left(\mathrm{kg} \cdot \mathrm{m}^{-1} \cdot \mathrm{s}^{-1}\right)$

$n \quad$ phenomenological coefficient (dimensionless)

$\rho \quad$ liquid density of water $\left(\mathrm{kg} \cdot \mathrm{m}^{-3}\right)$

SWP smectite weight percent (\%)

$t \quad$ time (s)

$\tau \quad$ shear stress $(\mathrm{Pa})$

$\tau_{o} \quad$ yield stress $(\mathrm{Pa})$

$\psi_{F P} \quad$ permittivity of the cake in the filter press $\left(\mathrm{s}^{-1}\right)$

$\psi_{O}$ permittivity of the GCL in the oedopermeameter $\left(\mathrm{s}^{-1}\right)$

\section{REFERENCES}

AFNOR (2002). XP P 84703 - Détermination de la capacité de gonflement de l'argile dans les géosynthétiques bentonitiques, $6 \mathrm{pp}$. 
AFNOR (2008). NF P 84-705 - Geosynthetic barriers - Determination of the swelling, flow and permeability characteristics of geosysnthetic clay liners (GCL) using an oedopermeameter - Characterisation test and performance test, $21 \mathrm{pp}$.

Abend, S. \& Lagaly, G. (2000). Sol-gel transitions of sodium montmorillonite dispersions. Applied Clay Science, 16, 201-227.

Barnes, H.A. (1999). The yield stress-a review or 'panta roi'-everything flows? Journal of Non-Newtonian Fluid Mechanic, 81, 133-178.

Besq, A., Malfoy, C., Pantet, A., Monnet, P. \& Righi, D. (2003). Physicochemical characterization and flow properties of some bentonite muds. Applied Clay Sciences, 23, 275-286.

Coussot, P. (2005). Rheometry of Pastes, Suspensions, and Granular Materials, Wiley, New York, $350 \mathrm{pp}$.

Coussot, P. (1997). Mudflow Rheology and Dynamics, IAHR Monograph, Balkema, Rotterdam, 260 pp.

Egloffstein, T.A. (2001). Natural bentonites - influence of the ion exchange and partial dessication on permeability and self-healing capacity of bentonites used in GCLs. Geotextiles and Geomembranes, 19, 427-444.

Guyonnet, D., Touze-Foltz, N., Norotte, V., Pothier, C., Didier, G., Gailhanou, H, Blanc, P. \& Warmont, F. (2009). Performance-based indicators for controlling geosynthetic clay liners in landfill applications, submitted to Geotextiles and Geomembranes.

Guyonnet, D., Touze-Foltz, N., Norotte, V., Pothier, C., Didier, G., Gailhanou, H., Blanc, Ph., Pantet, A., (2008). "Projet LIXAR2 - Indicateurs de performance pour les géosynthétiques bentonitiques. Project LIXAR2 - Performance indicators for geosynthetic clay liners. Final Report. BRGM Report No 56356-FR (in French). 
Guyonnet, D., Gaucher, E., Gaboriau, H., Pons, C.-H. Clinard, C., Norotte, V., Didier, G. (2005) - Geosynthetic clay liner interaction with leachate : correlation between permeability, microstructure, and surface chemistry. Journal of Geotechnical \& Geoenvironmental Engineering, 131(6), 740-749.

Keren, R. (1988). Rheology of aqueous suspensions of sodium/calcium montmorillonite. Soil Science Society of America Journal, 5, 924-928.

Kolstad, D., Benson, C. \& Edil, T. (2004). Hydraulic conductivity and swell of nonprehydrated geosynthetic clay liners permeated with multispecies inorganic solutions. Journal of Geotechnical and Geoenvironmental Engineering, 130, No. 12, 1236- 1249.

Lagaly, G. (2006). Colloid clay science, In Bergaya, F., Theng, B.K.G. and Lagaly, G. (Eds.), Handbook of Clay Science, Elsevier, pp. 141-246.

Lagaly, G. \& Ziesmer, S. (2003). Colloid chemistry of clay minerals: the coagulation of montmorillonite dispersions, Colloid and Interface Science, 100, 105-128.

Li, Y., Argillier, J.F., Rosenberg, E. \& Durrieu, J. (1997). Static and dynamic filtration properties of aqueous suspensions of clays and electrolytes. Revue de l'Institut Français du Pétrôle, 52, 207-218.

MEEDDAT (Ministère de l'Ecologie, de l'Energie, du Développement durable et de l'Aménagement du territoire), (2008). Guide de recommandations pour l'évaluation de l'équivalence en étanchéité passive d'installation de stockage de déchets, Version 2, 45 pp.

Mewis, J. (1979). Thixotropy - A general review. Journal of Non-Newtonian Fluid Mechanic, 6, 1-20.

Mujumbar, A., Beris, A., Metzner, A. (2001). Transient phenomena in thixotropic systems. Journal of Non-Newtonian Fluid Mechanic, 2072, 1-22. 
Pantet, A. \& Monnet, P. (2007). Liquid-solid transition of kaolinite suspensions, Mechanics of Materials, 39, 819-833.

Patterson, S.H. \& Murray, H.H. (1983). Clays, Industrial Minerals and Rocks, $5^{\text {th }}$ ed., Vol 1, S.J. Lafond (ed.), AIME New York, pp. 585-651.

Paumier, S. (2007). Facteurs déterminant l'organisation et la rhéologie du système argile-eau pour des suspensions de smectites. PhD Thesis, university of Poitiers, $205 \mathrm{pp}$.

Paumier, S., Pantet, A \& Monnet, P. (2008). Evaluation of the organization of the homoionic smectites layers $(\mathrm{Na}+$ or $\mathrm{Ca} 2+)$ in diluted dispersions using granulometry, microscopy and rheometry. Advances in Colloid and Interface Science, 141, 66-75.

Paumier, S., Pantet, A., Monnet, P. \& Touze-Foltz N. (2009). Evaluation of the viscoelastoplastic properties of a clay material using a flow curve. Applied Rheology, 19, 23824.

Pawlick, M., Laskowski, J.S. \& Ansari, A. (2003). Effect of carboxymethhyl cellulose and ionic strength on stability of mineral suspensions in potash ore flotation systems. Journal of Colloid and Interface Science, 260, 251-258.

Peysson, Y. (2004). Solid/liquid dispersions in drilling and production. Oil Gas Science Technical Review, IFP, 59, 11-21.

Pignon, F., Magnin, A. \& Piau, J.M. (1996). Thixotropic colloidal suspensions and flow curves with minimum: Identification of flow regimes and rheometric consequences. Journal of Rheology, 40, 573-587.

Schurz, J. (1990). The yield stress - an empirical reality. Rheologica Acta, 29, 170-171.

Sherwood, J.D. (1997). Initial and final stages of compressible filter cake compaction. AIChE Journal, 43, 1488-1493.

Tarleton, E.S. (1998). A new approach to variable pressure cake filtration. Minerals Engineering, 11, 53-69. 
Touze-Foltz, N., Lupo, J. \& Barroso, M. (2008). Geoenvironmental applications of geosynthetics. Keynote lecture, Proceedings EuroGeo4, 98 pp.

Uhlherr, P.H.T., Guo, J., Tiu, C., Zhang, X.M., Zhou, J.Z.Q. \& Fang, T.N. (2005). The shearinduced solid-liquid transition in yield stress materials with chemically different structures. Journal of Non-Newtonian Fluid Mechanic, 125, 101-119. 
Table 1 . The hydraulic conductivity $k_{O}$ of each GCL determined by Guyonnet et al. (2009) and the deduced permittivity $\psi_{O}$. The permittivity of each bentonite determined with the filter press $\psi_{F P}$ (this study).

\begin{tabular}{|c|c|c|c|c|}
\hline Bentonite & $k_{O}\left(\mathrm{~m}^{-1} \mathrm{~s}^{-1}\right)$ & $\psi_{O}\left(\mathrm{~s}^{-1}\right)$ & $\psi_{F P}\left(\mathrm{~s}^{-1}\right)$ & $\psi_{O} / \psi_{\mathrm{FP}}$ \\
\hline LX1 & $2.4 \times 10^{-11}$ & $2.90 \times 10^{-9}$ & $6.95 \times 10^{-9}$ & 2.49 \\
LX2 & $1.2 \times 10^{-11}$ & $1.35 \times 10^{-9}$ & $6.44 \times 10^{-9}$ & 4.78 \\
LX3 & $1.4 \times 10^{-11}$ & $1.47 \times 10^{-9}$ & $6.64 \times 10^{-9}$ & 4.51 \\
LX4 & $3.5 \times 10^{-11}$ & $3.61 \times 10^{-9}$ & $7.44 \times 10^{-9}$ & 2.06 \\
LX5 & $1.8 \times 10^{-11}$ & $2.60 \times 10^{-9}$ & $7.31 \times 10^{-9}$ & 2.81 \\
LX6 & $4.5 \times 10^{-9}$ & $6.52 \times 10^{-7}$ & $1.94 \times 10^{-8}$ & 0.03 \\
LX7 & $1.1 \times 10^{-11}$ & $1.68 \times 10^{-9}$ & $6.92 \times 10^{-9}$ & 4.12 \\
LX8 & $4.7 \times 10^{-10}$ & $3.97 \times 10^{-8}$ & $4.58 \times 10^{-8}$ & 1.15 \\
\hline
\end{tabular}


Table 2. Swell index obtained for each raw bentonite (Guyonnet et al. 2008) and the electrical conductivity of the bentonite dispersions.

\begin{tabular}{|c|l|c|c|}
\hline \multicolumn{2}{|c|}{ Bentonite } & \multirow{2}{*}{$\begin{array}{c}\text { Swell index } \\
{\left[\mathrm{cm}^{3} \cdot(2 \mathrm{~g})^{-1}\right]}\end{array}$} & $\begin{array}{c}\text { Electrical } \\
\text { conductivity } \\
(\mathrm{mS} / \mathrm{cm})\end{array}$ \\
\cline { 1 - 2 } Name & \multicolumn{1}{|c|}{ Type } & 34 & 2.9 \\
LX1 & sodium-activated calcium bentonites & 36 & 1.5 \\
LX2 & natural sodium bentonite & 31 & 1.5 \\
LX3 & natural sodium bentonite & 34 & 2.3 \\
LX4 & sodium-activated calcium bentonites & 29 & 2.4 \\
LX5 & sodium-activated calcium bentonites & 5 & 0.5 \\
LX6 & natural calcium bentonites & 31 & 2.3 \\
LX7 & sodium-activated calcium bentonites & 10 & 0.3 \\
LX8 & natural calcium bentonites & & \\
\hline
\end{tabular}


Table 3. Parameters resulting from modelling the descending portions of the rheograms for each bentonite dispersion.

\begin{tabular}{|l|c|c|c|c|c|}
\hline \multirow{2}{*}{ Bentonites } & \multicolumn{2}{|c|}{ Bingham's parameters } & \multicolumn{3}{|c|}{ Herschel Bulkley's parameters } \\
\cline { 2 - 6 } & $\tau_{0}$ & $\eta_{B}$ & $\tau_{0}$ & $\kappa$ & $n$ \\
\hline LX1 & 91 & 0.97 & & & \\
LX2 & & & 9.6 & 0.74 & 0.66 \\
LX3 & & & 6.3 & 0.65 & 0.71 \\
LX4 & 38 & 0.05 & & & \\
LX5 & & & 31 & 1.91 & 0.40 \\
LX7 & 50 & 0.10 & & & \\
\hline
\end{tabular}




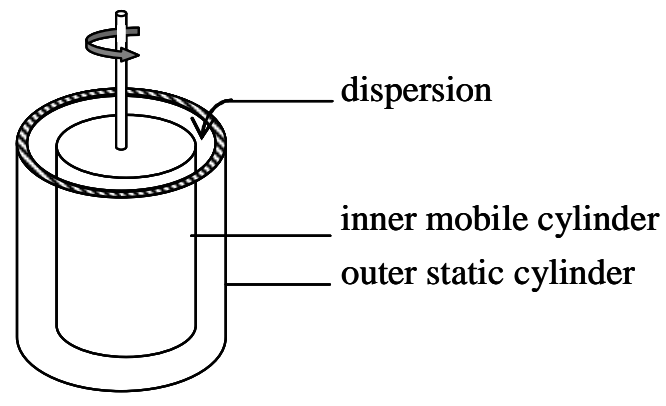

a)

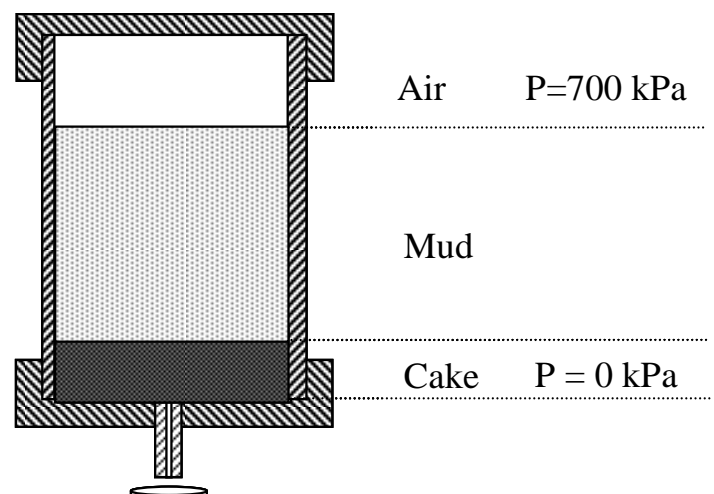

b)

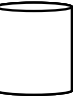

Figure 1. Schematic of the rheometer geometry (a) and the filter press cell (b). 

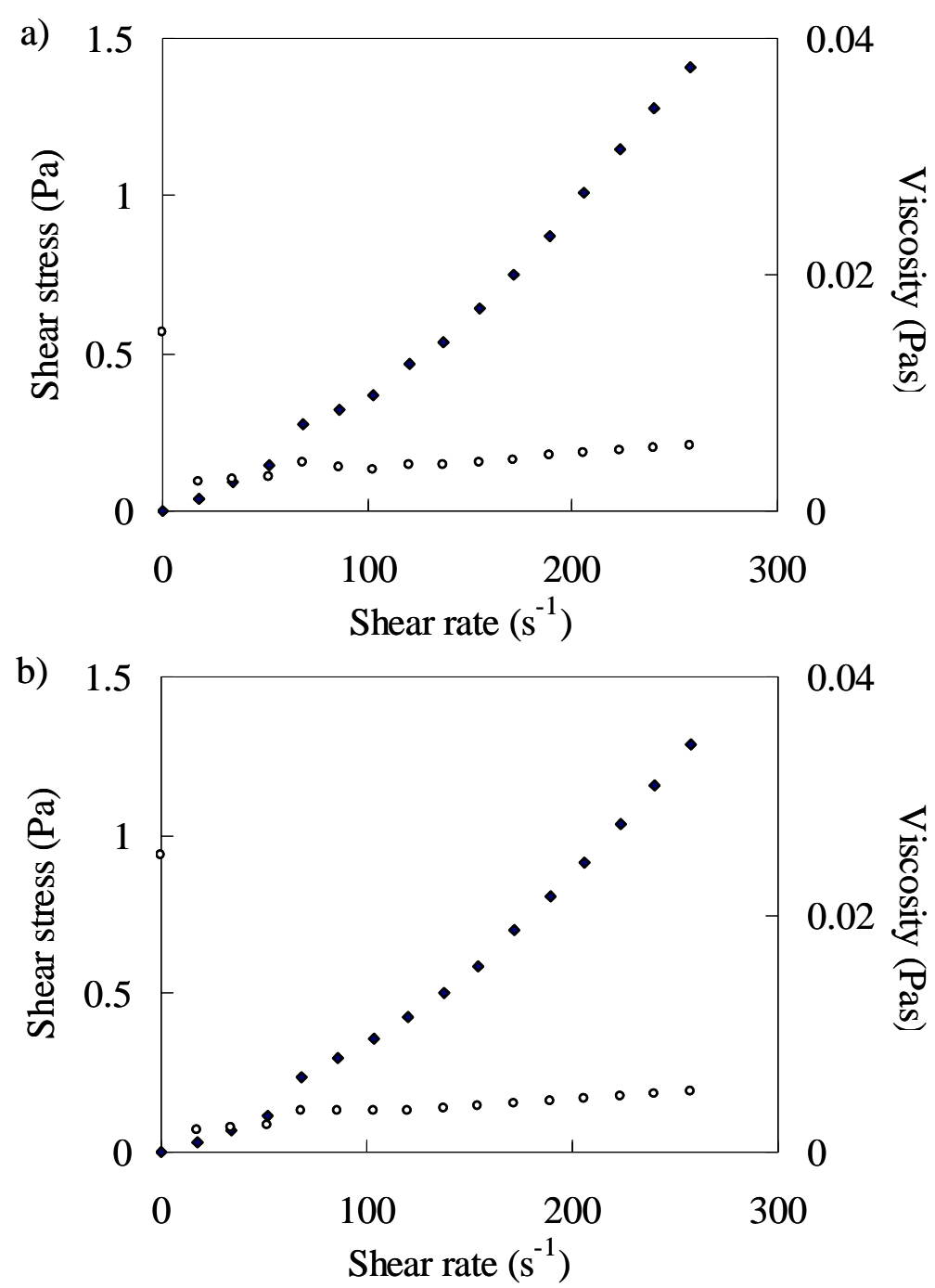

Figure 2. Flow curves for raw bentonites dispersions of LX6 (a) and LX8 (b) in $\mathrm{NaCl}$ $1 \mathrm{mM}$ at $10 \%$. 


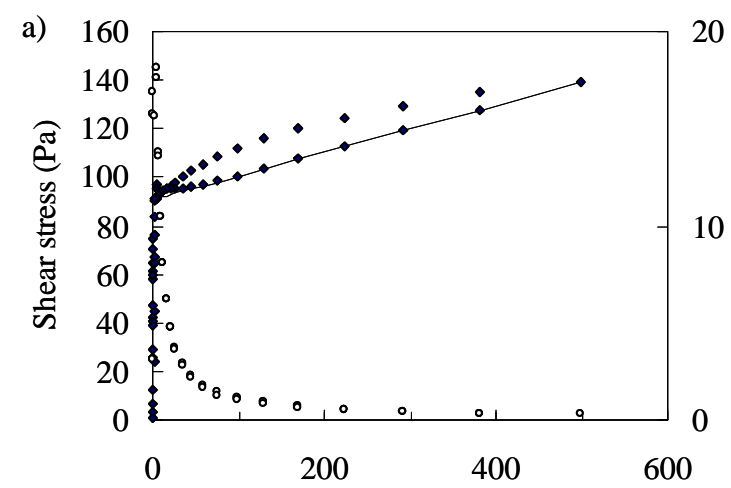

Shear rate $\left(\mathrm{s}^{-1}\right)$

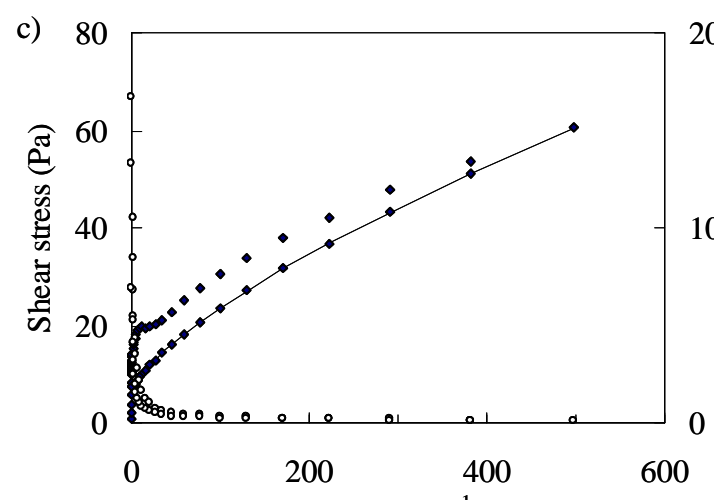

Shear rate $\left(\mathrm{s}^{-1}\right)$

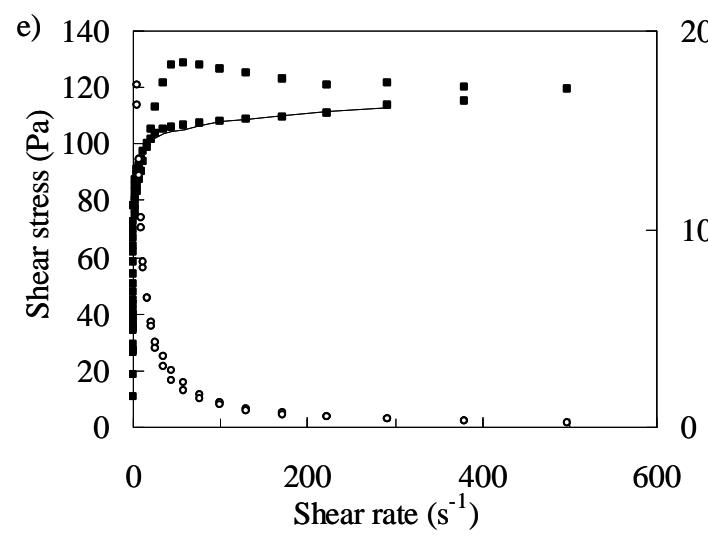

20

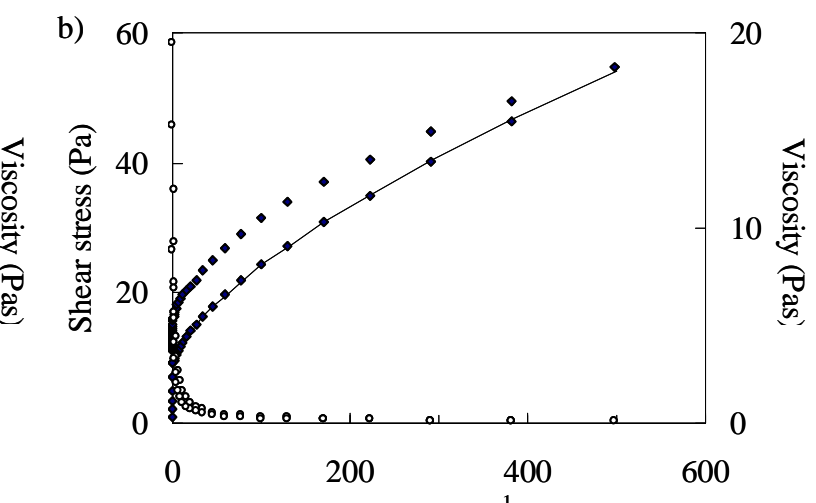

Shear rate $\left(\mathrm{s}^{-1}\right)$

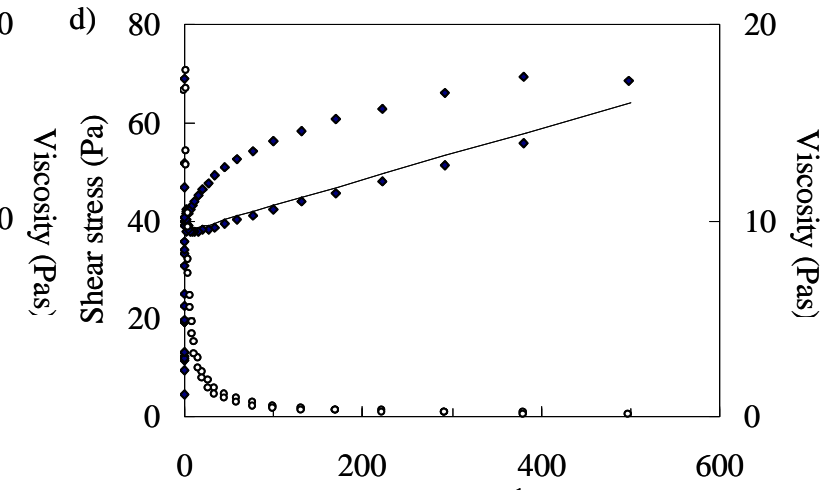

Shear rate $\left(\mathrm{s}^{-1}\right)$

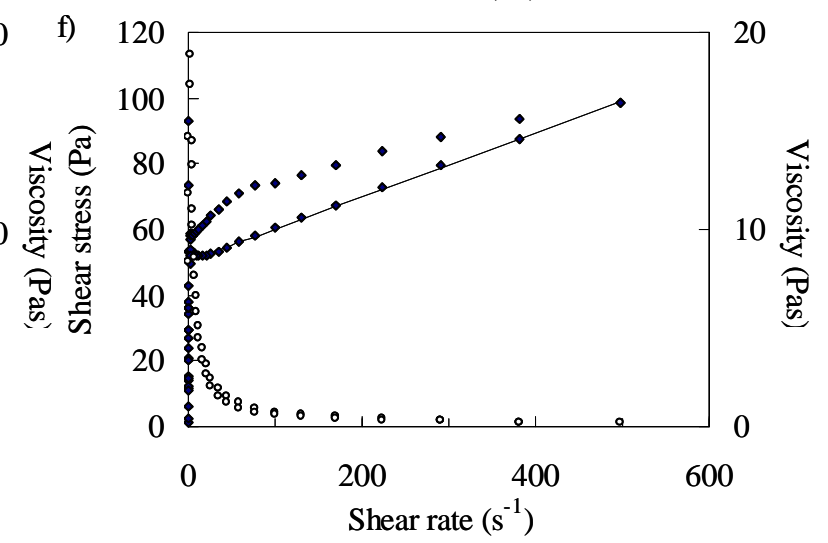

model of the descending part of the flow curve

Figure 3. Flow curves for raw bentonites dispersions of LX1 (a), LX2 (b), LX3 (c), LX4 (d), LX5 (e) and LX7 (f) at 10\% in $\mathrm{NaCl} 1 \mathrm{mM}$. 


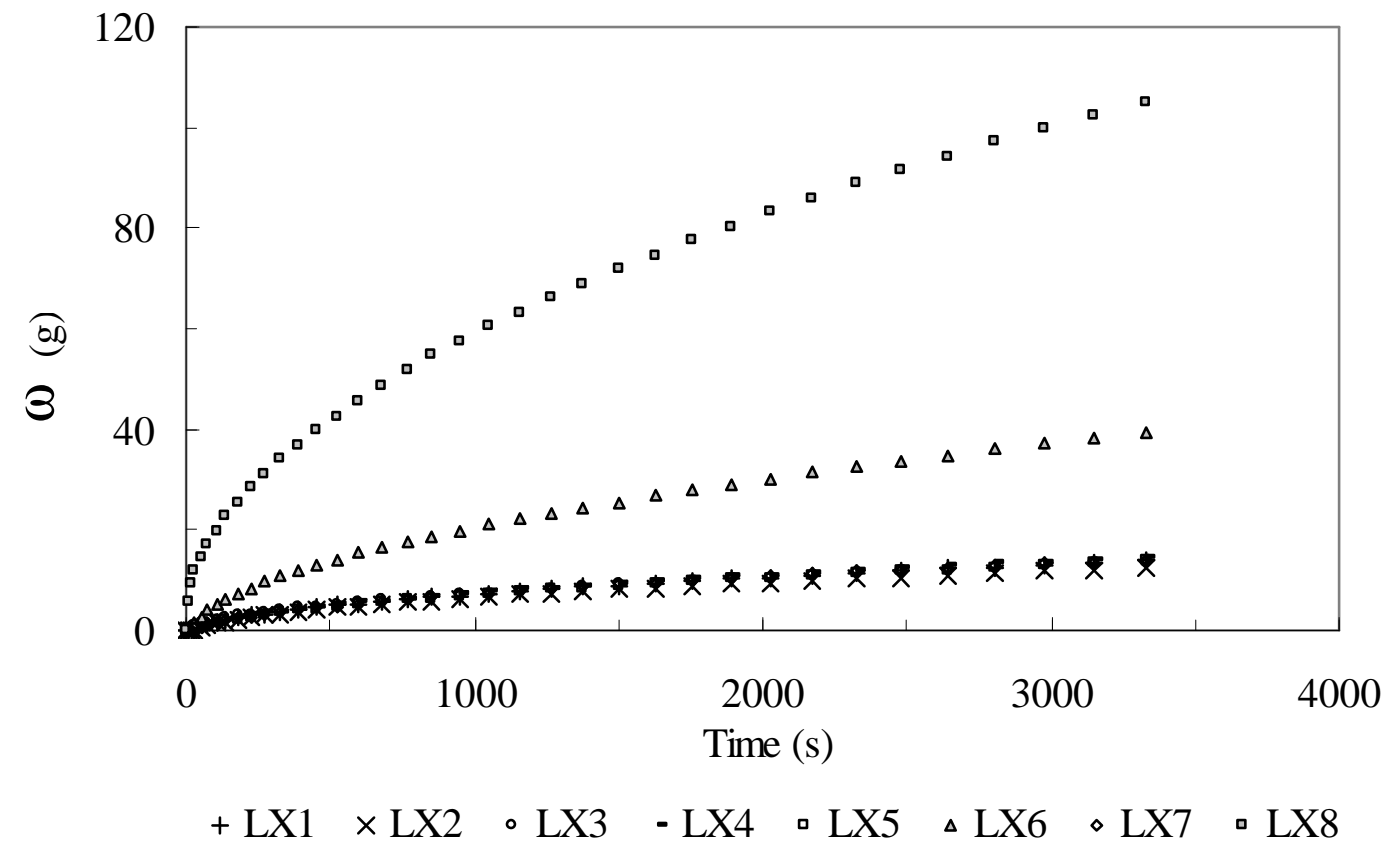

Figure 4. Filtration curves obtained for each bentonite dispersions at a concentration of $10 \%$. 


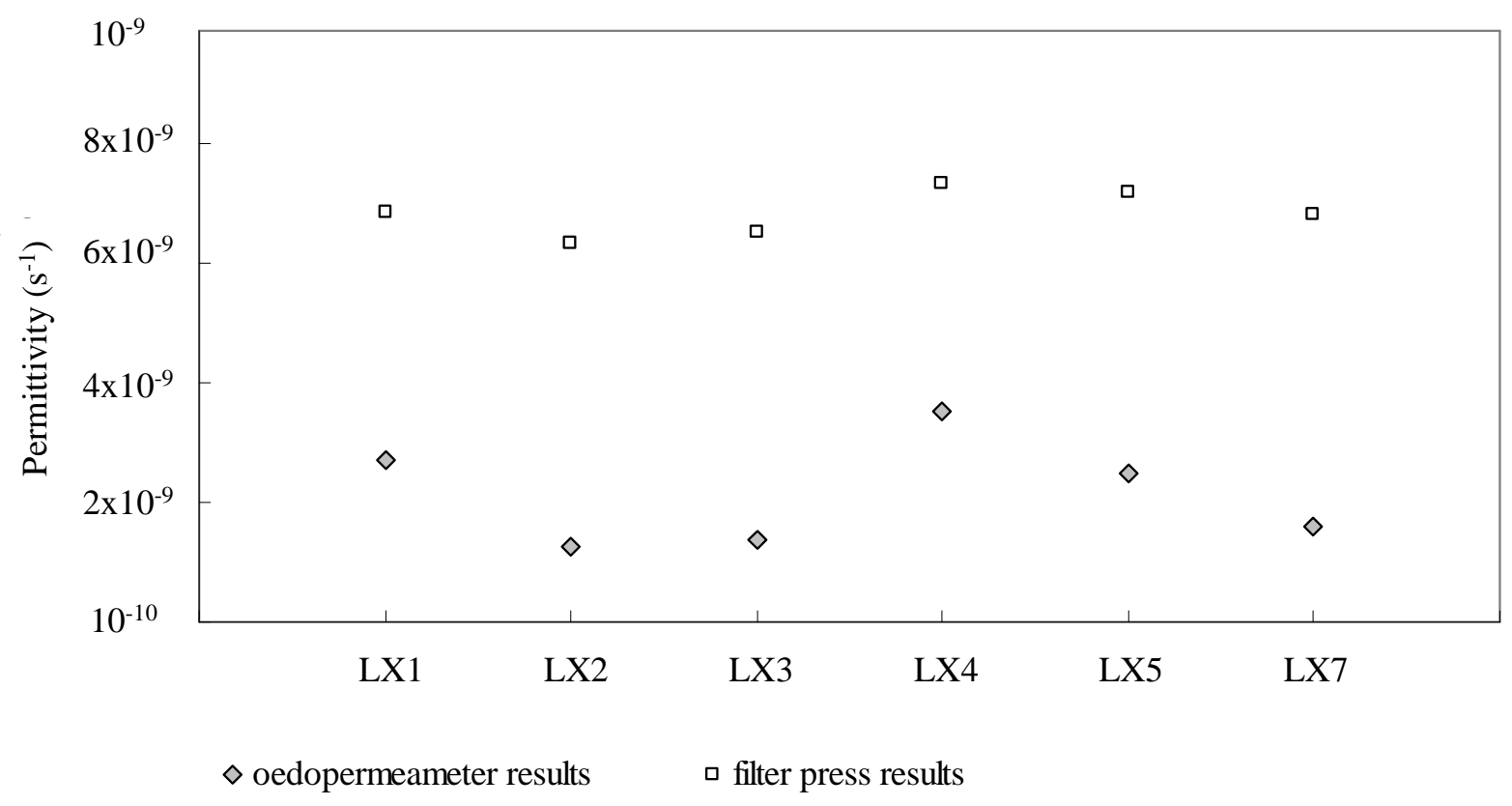

Figure 5. Comparison of the permittivities obtained with the oedopermeameter tests and the filter press tests for each material. 


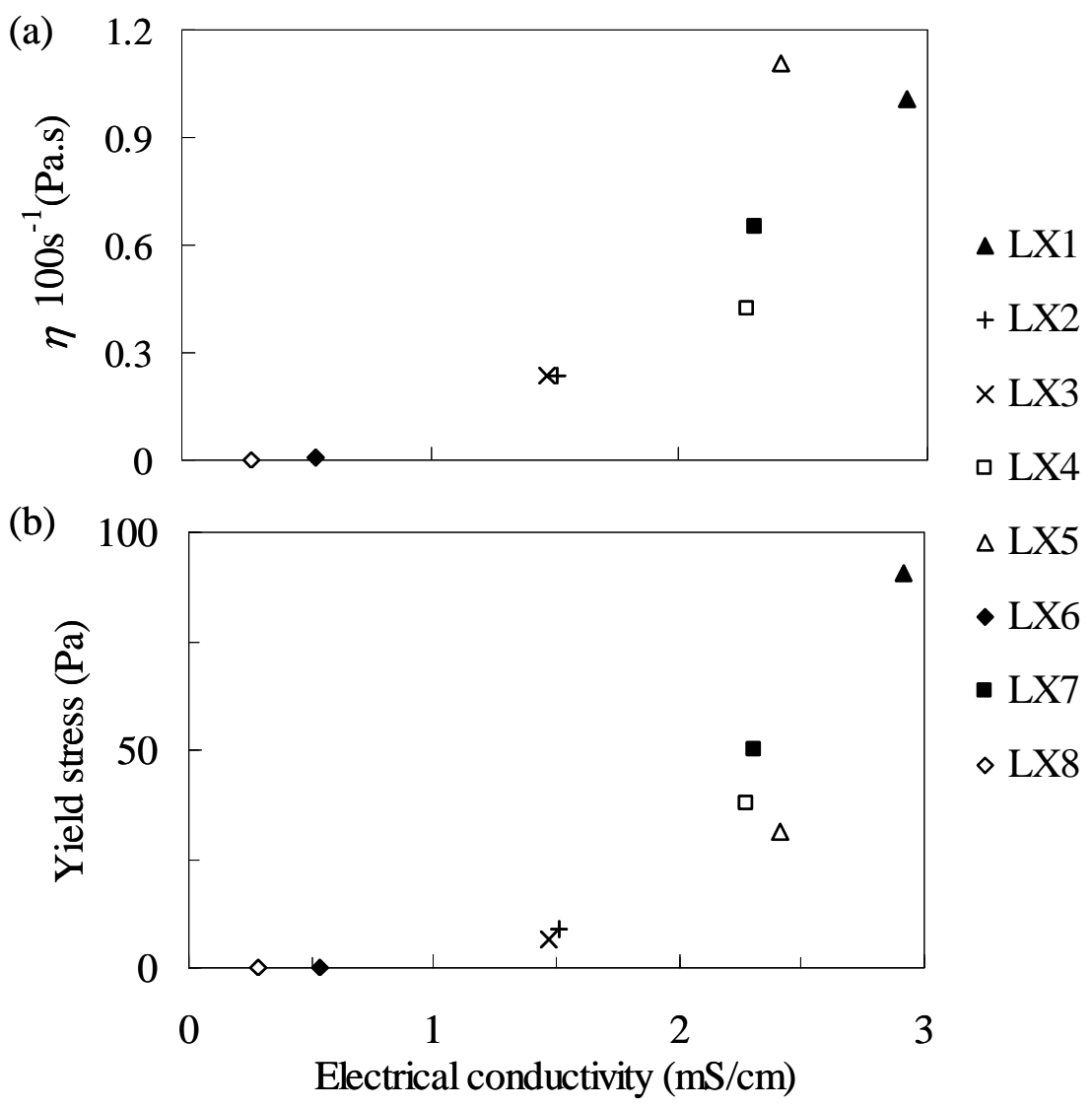

Figure 6. Relationship between (a) the yield stress $\tau_{0}$ and (b) the apparent viscosity at $100 \mathrm{~s}^{-1}$ $\left(\eta 100 \mathrm{~s}^{-1}\right)$ determined from the rheometer tests and the electrical conductivities. 